\title{
The Effect of Information Technology on Healthcare Improvement from Clinicians' Perspective
}

\author{
Farahnaz Sadoughi $^{1}$, Mahtab Karami ${ }^{2}$, Gholam Abbas Mousavi ${ }^{3}$ \& Afsaneh Karimi ${ }^{1,4}$ \\ ${ }^{1}$ Department of Health Information Management, School of Health Management and Information Sciences, Iran \\ University of Medical Sciences, Tehran, Iran \\ ${ }^{2}$ Health Information Management Research Center (HIMRC), Department of Health Information Technology \\ and Management, School of Allied-Medical Sciences, Kashan University of Medical Sciences, Kashan, Iran \\ ${ }^{3}$ Department of Statistics and Public Health, Trauma Research Center, School of Health, Kashan University of \\ Medical Sciences, Kashan, Iran \\ ${ }^{4}$ Health Information Technology Department, Paramedical School, Zahedan University of Medical Sciences, \\ Zahedan, Iran \\ Correspondence: Afsaneh Karimi, Department of Health Information Management, School of Health \\ Management and Information Sciences, Iran University of Medical Sciences, No. 6, Rashidi Yasemi St. Vali- e \\ Asr St. Vanak Sq., Tehran, Iran. Tel: 98-913-270-3876. E-mail: k_afsaneh463@yahoo.com, \\ Afsanehkarimi2014@gmail.com
}

Received: April 30, 2016 Accepted: June 13, 2016 Online Published: July 11, 2016

doi:10.5539/gjhs.v9n3p128 URL: http://dx.doi.org/10.5539/gjhs.v9n3p128

\begin{abstract}
Objective: This study investigated the perspective of clinicians about the effect of information technology (IT) on healthcare improvement.

Methods: This cross-sectional study conducted in 2014-15, developed a questionnaire to evaluate of the perspective of 281 employees at two general hospitals affiliated with Zahedan University of Medical Sciences to measure the effect of IT on improving the healthcare system. The data was analyzed using the descriptive Kolmogorov-Smirnov and Kruskal-Wallis tests. One-way ANOVA was used to compare groups.

Results: The overall attitude of the research population about the effect of IT on healthcare was positive, with an average score of $3.29 \pm 0.90$. The most influential effects of IT on the healthcare were accelerated diagnosis and treatment. The use of standardized messaging was the most effective approach for improving the healthcare system. Developing a standard mechanism for protection of data and establishing clear rules for acceptance of computer documentation by the judicial authorities were the most influential cases to increase IT effects in the healthcare system.

Conclusion: Physicians play important roles in the successful implementation of IT because they are directly involved in the treatment of patients. Their opinions should be considered when providing or creating any type of system. The importance of budgeting for IT should be considered, because applying these systems can be capital intensive. Because application of such systems requires acceptance by legal circles of the information obtained, it is necessary for preparations to be made.
\end{abstract}

Keywords: perspective, users, Information technology

\section{Introduction}

Information technology (IT) has transformed the infrastructure of human life (Hosseini \& Asefzadeh, 2009; Nasiripour, Rahmani, Radfar, \& Najafbeigi, 2012; Rezaeihachesoo, Fozoonkhah, Safaei, \& Afshar, 2010). The healthcare sector is one area that has been strongly affected by IT (Hosseini \& Asefzadeh, 2009; Nasiripour et al., 2012; Ajami, Ketabi, Saghaeiannejad, \& Heidari, 2010; Barzekar \& Karami, 2014). The goal of applying IT to healthcare is to accelerate the collection of and ease of access to information. This requires support in the form of effective decision-making by the management of the system. The importance of information and communication technology in medical and health care cannot be overemphasized (Kumar, 2012) because its application is essential for solving health problems (Hosseini \& Asefzadeh, 2009). 
According to literature review there are different application areas of IT including hospital management (Ferrara, 1996) (for example, in order to collecting, processing, and analyzing of information to make right decision, Budgeting, and planning (Baghbaniyan \& Ghanehpour, 2000; Trimm, 1990), patient registration, and digital imaging (Rozenblum et al., 2011).

In deprived areas due to various diseases, using IT can have multiple benefits such as improvement in quality of healthcare and reduces of disease outbreaks through quick access to clinical and statistical information and also access to clinicians without the need to refer patients to medical centers. In addition, using IT significantly reduces the costs (Nasiripour et al., 2012; Karami, 2015).

Healthcare system reform planning is a serious priority of Iran Ministry of Health programs. The strengthening of the hospital information system, commitment to implementation of electronic health records, and development of a national system for recording the health statistics have been administrative requirements to achieve this transformation since early in 2014 (Nematbakhsh, 2015). All of these requirements depend on the application of IT in the healthcare sector. The evaluation of organizational readiness for adoption and implementation of these technologies is the first and most important step (Ajami et al., 2010).

Since the successful implementation of IT requires user acceptance and appropriate infrastructure (Shokrizadeharani \& Karami, 2012; Buntin, Burke, Hoaglin, \& Blumenthal, 2011), this study assessed the perspective of clinicians from two general hospitals affiliated with Zahedan university of Medical Sciences (in southeastern of Iran) about the effect of IT on healthcare to determine the readiness of these centers for application of IT. The province of Sistan-Va-Balochestan is some distance from the center of Iran. It is a large area with widely-scattered towns. The application of IT can result the fair distribution of healthcare services in this province and for access by residents to a variety of healthcare services.

\section{Methods}

This cross-sectional study included 941 clinicians from two general hospitals affiliated with Zahedan University of Medical Sciences. They included physicians, nurses, and paramedical clinicians (laboratory, midwifery, radiology, anesthesia, and operating room clinicians, and health information management). The research sample size of 281 clinicians was calculated using the Morgan table by stratified sampling.

The Hospitals, In this study, have the Hospital Information Systems (HIS) for more than 15 years and are using multiple computerized equipment for diagnostic and treatment such as PACS (Picture Archiving and Communication System). And also, they provide Tele-consulting services to other districts and cities in province.

A four-part questionnaire was developed by the researchers and used to collect data. The first part contained the demographic data of the research population (age, gender, level of education, field of study, and job experience). The second part included 18 questions related to the effect of IT on healthcare. The third part contained 9 questions on the effect of proposed solutions to improve the healthcare system. The fourth part contained 15 questions related to the effect of the proposed solutions for increasing the effect of IT in the healthcare system.

The reliability of the questionnaire was evaluated using the test-retest method and a Cronbach's alpha coefficient of $98 \%$; its validity was assessed by content validity. The questions offered six possible responses: I do not know, very low, low, medium, high, and very high that were assigned scores of 0 to 5 , respectively. The evaluation criteria for the effect of IT had an average score of 3. A lower score was considered to be undesirable and a higher score was considered to be desirable. The scores were considered to reflect the positive and negative general attitudes of the clinicians.

The descriptive statistics of average and standard deviation (SD) were used to report the findings. The Kolmogorov-Smirnov, Kruskal-Wallis, One-way ANOVA, and Pearson's correlation coefficient were used for comparison of groups. SPSS, version 15, software was employed for calculation.

\section{Results}

The demographic characteristics indicated that $69 \%$ of the research population was female. The average age was $30.81 \pm 5.8$ years, with a majority of participants (53.7\%) falling into the 20-29 years range. Most $(60.5 \%)$ had less than 5 years of job experience, $76.5 \%$ had bachelor degrees, and $59.1 \%$ were employed as nurses (Table 1). 
Table 1. Frequency distribution of clinician demographic characteristics

\begin{tabular}{|c|c|c|c|c|c|c|c|c|c|c|c|c|c|c|c|c|c|}
\hline \multirow[b]{2}{*}{ 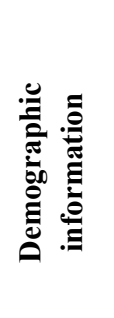 } & \multicolumn{2}{|c|}{ Gender } & \multicolumn{3}{|l|}{ Age } & \multicolumn{4}{|c|}{ Education } & \multicolumn{3}{|c|}{ Field } & \multicolumn{5}{|c|}{ Job experience } \\
\hline & $\begin{array}{l}\frac{\mathscr{U}}{\overparen{\Xi}} \\
\end{array}$ & $\begin{array}{l}\frac{0}{\pi} \\
\text { E्U }\end{array}$ & خે̀ & ले & 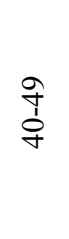 & $\stackrel{\curvearrowright}{\wedge}$ & 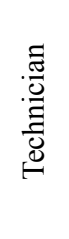 & $\begin{array}{l}\ddot{0} \\
\frac{0}{0} \\
\tilde{0} \\
\ddot{n}\end{array}$ & 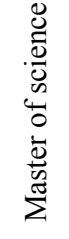 & $\frac{\hat{2}}{2}$ & $\frac{\sqrt{\frac{\pi}{0}}}{\frac{0}{\sqrt{2}}}$ & $\begin{array}{l}\mathscr{D} \\
\vdots \\
\Xi\end{array}$ & 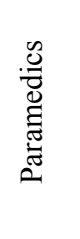 & 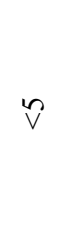 & $\frac{n}{n}$ & $\begin{array}{l}\stackrel{2}{n} \\
\stackrel{1}{n}\end{array}$ & $\stackrel{\wedge}{\wedge}$ \\
\hline Number & 194 & 87 & 151 & 96 & 32 & 2 & 27 & 215 & 6 & 33 & 33 & 166 & 82 & 170 & 88 & 22 & 1 \\
\hline Percent & 69 & 31 & 53.7 & 34.2 & 11.4 & 0.7 & 9.6 & 76.5 & 2.1 & 11.7 & 11.7 & 59.1 & 29.2 & 60.5 & 31.3 & 7.8 & 0.4 \\
\hline
\end{tabular}

The overall view of the research population was positive towards the effect of IT on the promotion of healthcare, with an average score of $3.29 \pm 0.90$. The average score for the effect of IT on healthcare was $2.99 \pm 0.76$, the effect of proposed solutions on improving healthcare was $3.52 \pm 0.78$, and the effect of proposed solutions for increasing the effect of IT in the healthcare system was $3.36 \pm 2.07$.

Table 2 indicates that the highest effect of IT on healthcare was the acceleration of diagnosis and treatment (3.70 $\pm 1.36)$, increasing productivity $(3.59 \pm 1.67)$, and medical research $(3.23 \pm 1.33)$ by the research population. Physicians had more positive views on this than the other employees with average scores of $3.08 \pm 0.74$; this produced the highest scores for effect of IT on medical research at $3.23 \pm 1.33$.

Table 2. Clinicians' perspective about effect of IT on healthcare

\begin{tabular}{|c|c|c|c|c|c|c|c|c|c|}
\hline \multirow{2}{*}{ Options } & \multicolumn{2}{|l|}{ Total } & \multicolumn{2}{|c|}{ Physician } & \multicolumn{2}{|l|}{ Nurse } & \multicolumn{2}{|c|}{ Paramedics } & \multirow{2}{*}{ p-value } \\
\hline & Mean & $\mathrm{SD}$ & Mean & SD & Mean & $\mathrm{SD}$ & Mean & SD & \\
\hline Self-treatment & 2.33 & 1.36 & 3.00 & 1.37 & 2.11 & 1.31 & 2.49 & 1.35 & 0.00 \\
\hline Incidence of medical errors & 2.71 & 1.26 & 2.52 & 1.30 & 2.68 & 1.17 & 2.84 & 1.40 & 0.24 \\
\hline Medical research & 3.23 & 1.33 & 3.79 & 1.08 & 3.23 & 1.28 & 2.98 & 1.44 & 0.02 \\
\hline Increase in clinician motivation & 3.00 & 1.19 & 3.30 & 1.07 & 2.91 & 1.25 & 3.05 & 1.10 & 0.28 \\
\hline Clinician satisfaction & 3.10 & 2.18 & 3.18 & 1.29 & 2.96 & 1.18 & 3.34 & 3.59 & 0.50 \\
\hline Distance and continuing education & 3.05 & 1.45 & 3.12 & 1.60 & 3.02 & 1.50 & 3.06 & 1.32 & 0.60 \\
\hline Unnecessary patient admissions & 2.79 & 1.40 & 2.97 & 1.33 & 2.86 & 1.39 & 2.59 & 1.45 & 0.26 \\
\hline Repetitive works and lab tests & 2.93 & 1.38 & 3.21 & 1.43 & 3.01 & 1.39 & 2.67 & 1.32 & 0.04 \\
\hline Evaluation of care to individual & 3.17 & 3.27 & 2.88 & 1.36 & 3.35 & 4.10 & 2.93 & 1.28 & 0.47 \\
\hline Production of information resources & 3.05 & 1.39 & 3.03 & 1.49 & 3.02 & 1.36 & 3.12 & 1.43 & 0.73 \\
\hline $\begin{array}{l}\text { Assessment of accuracy and validity of national } \\
\text { trade }\end{array}$ & 3.11 & 1.38 & 3.30 & 1.42 & 3.11 & 1.33 & 3.05 & 1.47 & 0.54 \\
\hline $\begin{array}{l}\text { Alteration and overwriting data and violation of } \\
\text { legal rights of patients }\end{array}$ & 3.02 & 1.40 & 3.06 & 1.52 & 3.05 & 1.39 & 2.96 & 1.40 & 0.65 \\
\hline Integration of health information & 3.22 & 1.26 & 3.03 & 1.40 & 3.31 & 1.19 & 3.10 & 1.33 & 0.33 \\
\hline Support consultations & 3.08 & 1.80 & 2.97 & 1.51 & 3.20 & 2.02 & 2.87 & 1.38 & 0.48 \\
\hline Telemedicine & 3.02 & 1.33 & 2.79 & 1.39 & 3.04 & 1.29 & 3.07 & 1.40 & 0.52 \\
\hline Increasing productivity & 3.59 & 1.67 & 3.09 & 1.89 & 3.70 & 1.67 & 3.59 & 1.56 & 0.16 \\
\hline Reducing costs & 2.87 & 2.25 & 2.94 & 2.29 & 2.91 & 2.24 & 2.77 & 2.28 & 0.88 \\
\hline Accelerating diagnosis and treatment & 3.70 & 1.36 & 3.09 & 1.55 & 3.75 & 1.33 & 3.83 & 1.28 & 0.02 \\
\hline Total & 2.99 & 0.76 & 3.08 & 0.74 & 2.99 & 0.76 & 2.94 & 0.79 & 0.68 \\
\hline
\end{tabular}


Table 3 shows that the average score for standardized messaging was $3.70 \pm 2.58$, integration of patient record systems was $3.65 \pm 1.05$, identification system was $3.64 \pm 1.08$, and access to clinical examinations was $3.64 \pm$ 1.04. These were the most effective strategies in the opinions of the study population. In these categories, the viewpoints of physicians were more positive than the other personnel with an average score of $3.73 \pm 0.69$.

Table 3. Clinicians' perspective about effect of solutions on healthcare improvement

\begin{tabular}{|c|c|c|c|c|c|c|c|c|c|}
\hline \multirow{2}{*}{ Options } & \multicolumn{2}{|l|}{ Total } & \multicolumn{2}{|c|}{ Physician } & \multicolumn{2}{|l|}{ Nurse } & \multicolumn{2}{|c|}{ Paramedics } & \multirow{2}{*}{ p-value } \\
\hline & Mean & SD & Mean & SD & Mean & SD & Mean & SD & \\
\hline Development of electronic health records & 3.37 & 1.41 & 3.76 & 1.15 & 3.30 & 1.41 & 3.37 & 1.50 & 0.19 \\
\hline Establishment of clinical data repositories & 3.51 & 1.12 & 3.88 & 1.08 & 3.46 & 1.10 & 3.46 & 1.16 & 0.09 \\
\hline Clinical documentation & 3.53 & 1.08 & 3.85 & 0.91 & 3.52 & 1.00 & 3.43 & 1.28 & 0.23 \\
\hline Computerized physician orders & 3.34 & 1.13 & 3.52 & 1.23 & 3.21 & 1.12 & 3.52 & 1.08 & 0.04 \\
\hline Decision support systems & 3.29 & 1.19 & 3.21 & 1.54 & 3.23 & 1.14 & 3.44 & 1.16 & 0.31 \\
\hline Integration of patient records system & 3.65 & 1.05 & 4.06 & 0.70 & 3.61 & 1.01 & 3.59 & 1.21 & 0.07 \\
\hline Access to clinical examinations & 3.64 & 1.04 & 3.67 & 1.22 & 3.60 & 0.94 & 3.72 & 1.16 & 0.41 \\
\hline Using the messaging Standards & 3.70 & 2.58 & 3.73 & 1.28 & 3.55 & 1.01 & 4.01 & 4.48 & 0.34 \\
\hline Identity determination system & 3.64 & 1.08 & 3.94 & 1.00 & 3.61 & 1.07682 & 3.57 & 1.12 & 0.21 \\
\hline Total & 3.52 & 0.78 & 3.73 & 0.69 & 3.46 & 0.69 & 3.57 & 0.96 & 0.14 \\
\hline
\end{tabular}

Table 4 revealed that the most effective strategies for increasing the effect of IT on the healthcare system were; development of standard mechanisms to protect the confidentiality and security of data $(3.40 \pm 2.75)$, creation of standard rules for acceptance of computer documentation by the judiciary $(3.36 \pm 2.59)$, definition and determination of work requirements and priorities $(3.36 \pm 3.36)$, development of positive viewpoints of organizations providing the healthcare services towards the application of IT $(3.32 \pm 1.57)$, and appropriate budgeting based on the requirements, conditions, and opportunities $(3.29 \pm 2.79)$. Paramedical clinicians had the most positive attitudes towards these issues with an average score of $3.62 \pm 3.58$. They believed that use of the media had the greatest effect on the increase in effect of IT on the healthcare system with an average of $3.40 \pm$ 1.36 .

Table 4. Clinicians' perspective about solutions for increasing effect of IT

\begin{tabular}{|c|c|c|c|c|c|c|c|c|c|}
\hline \multirow{2}{*}{ Options } & \multicolumn{2}{|l|}{ Total } & \multicolumn{2}{|c|}{ Physician } & \multicolumn{2}{|l|}{ Nurse } & \multicolumn{2}{|c|}{ Paramedics } & \multirow{2}{*}{ p-value } \\
\hline & Mean & SD & Mean & SD & Mean & SD & Mean & $\mathrm{SD}$ & \\
\hline $\begin{array}{l}\text { Creating favorable } \\
\text { evaluation systems and } \\
\text { continuous monitoring } \\
\text { programs }\end{array}$ & 2.93 & 1.44 & 2.76 & 1.64 & 2.92 & 1.44 & 3.04 & 1.36 & 0.70 \\
\hline Use of media & 3.22 & 1.31 & 3.27 & 1.28 & 3.12 & 1.33 & 3.40 & 1.28 & 0.22 \\
\hline $\begin{array}{l}\text { Creating a positive } \\
\text { viewpoint in } \\
\text { organizations providing } \\
\text { health services towards } \\
\text { application of IT }\end{array}$ & 3.32 & 1.57 & 3.36 & 1.08 & 3.31 & 1.83 & 3.33 & 1.09 & 0.76 \\
\hline $\begin{array}{l}\text { Development of strategic } \\
\text { plans to reform } \\
\text { healthcare system }\end{array}$ & 3.17 & 1.20 & 3.15 & 1.44 & 3.22 & 1.12 & 3.10 & 1.26 & 0.76 \\
\hline
\end{tabular}




\begin{tabular}{|c|c|c|c|c|c|c|c|c|c|}
\hline $\begin{array}{l}\text { Private sector } \\
\text { participation }\end{array}$ & 3.18 & 2.63 & 3.03 & 1.49 & 3.28 & 3.24 & 3.02 & 1.27 & 0.94 \\
\hline $\begin{array}{l}\text { Determination and } \\
\text { definition of needs and } \\
\text { priorities of users }\end{array}$ & 3.36 & 3.36 & 3.15 & 1.39 & 3.58 & 4.21 & 2.99 & 1.39 & 0.70 \\
\hline $\begin{array}{l}\text { Developing cultural } \\
\text { infrastructure }\end{array}$ & 3.19 & 2.11 & 2.94 & 1.52 & 3.28 & 2.47 & 3.11 & 1.43 & 0.80 \\
\hline $\begin{array}{l}\text { Simplifying and updating } \\
\text { systems }\end{array}$ & 3.32 & 1.33 & 3.00 & 1.37 & 3.34 & 1.37 & 3.31 & 1.33 & 0.20 \\
\hline $\begin{array}{l}\text { Identity confidentiality } \\
\text { and security of data } \\
\text { mechanisms }\end{array}$ & 3.40 & 2.75 & 3.48 & 1.28 & 3.43 & 3.39 & 3.29 & 1.44 & 0.60 \\
\hline $\begin{array}{l}\text { Developing specific rules } \\
\text { for admission of } \\
\text { computer evidence to } \\
\text { judiciary }\end{array}$ & 3.36 & 2.59 & 3.48 & 1.28 & 3.42 & 3.17 & 3.18 & 1.44 & 0.54 \\
\hline $\begin{array}{l}\text { Development of } \\
\text { standards which facilitate } \\
\text { data storage for records } \\
\text { of patients in information } \\
\text { network }\end{array}$ & 3.24 & 1.35 & 3.09 & 1.35 & 3.30 & 1.32 & 3.20 & 1.40 & 0.57 \\
\hline $\begin{array}{l}\text { Proper budgeting based } \\
\text { on requirements and } \\
\text { conditions }\end{array}$ & 3.29 & 2.79 & 3.15 & 1.56 & 3.41 & 3.41 & 3.10 & 1.52 & 0.97 \\
\hline $\begin{array}{l}\text { Identifying obstacles to } \\
\text { proper application of IT }\end{array}$ & 3.26 & 1.37 & 3.24 & 1.60 & 3.21 & 1.35 & 3.38 & 1.33 & 0.59 \\
\hline $\begin{array}{l}\text { Establishment of pilot } \\
\text { projects }\end{array}$ & 2.93 & 1.56 & 2.48 & 1.70 & 2.96 & 1.50 & 3.04 & 1.62 & 0.20 \\
\hline Total & 3.36 & 2.07 & 3.11 & 0.86 & 3.29 & 0.87 & 3.62 & 3.58 & 0.65 \\
\hline
\end{tabular}

The relationship between the viewpoints of the research population towards the impact of IT on healthcare improvement and the occupations of research population demonstrated a significant relationship between the options of self-treatment, medical research, eliminating repetition of work, accelerating diagnosis and treatment, and computerized physician orders as the most effective approaches in improving the healthcare system (Tables 2 and 3).

The relationship between the perspective of the research population towards the effect of IT on healthcare, the effect of proposed solutions on healthcare improvement, and the effect of proposed solutions for increasing the effect of IT in the health sector showed a significant and positive correlation in the physician group over the other groups. A positive correlation was also shown for nurse group; however, this correlation coefficient was lower than that for the physician group. The paramedics group showed a positive relationship between the effect of IT on healthcare and the effect of proposed solutions for increasing the effect of IT on the healthcare system. The correlation coefficient here was also lower than those for the physician and nurse groups. All showed statistical significance and a positive correlation (Table 5). 
Table 5. Correlation between factors in study groups

\begin{tabular}{lllll}
\hline Relations & & b\&d & b\&j & d\&j \\
\hline \multirow{2}{*}{ Physician } & $\mathrm{r}$ & 0.6 & 0.4 & 0.6 \\
& $\mathrm{PV}$ & $<0.001$ & 0.068 & $<0.001$ \\
\hline \multirow{2}{*}{ Nurse } & $\mathrm{r}$ & 0.379 & 0.369 & 0.797 \\
& $\mathrm{PV}$ & $<0.001$ & $<0.001$ & $<0.001$ \\
\hline \multirow{2}{*}{ Paramedics } & $\mathrm{r}$ & 0.143 & 0.352 & 0.162 \\
& $\mathrm{PV}$ & 0.19 & $<0.001$ & 0.14 \\
\hline \multirow{2}{*}{ Total } & $\mathrm{r}$ & 0.19 & 0.36 & 0.23 \\
& $\mathrm{PV}$ & $<0.001$ & $<0.001$ & $<0.001$ \\
\hline
\end{tabular}

Note. b: Clinicians perspective about effect of IT on healthcare.

d: Clinicians perspective about solutions for increasing the effect of IT.

$\mathrm{j}$ : Clinicians perspective about effect of solutions on improving healthcare.

\section{Discussion}

The results of this research indicate that the viewpoint of the research population towards the effect of IT for promoting the healthcare system was positive. This is consistent with the results of other studies (Dargahi, Mahmoodi, \& Torabi, 2006; Shokrizadeharani, \& Karami, 2012). The use of IT in the field of healthcare was found to improve the healthcare system and increase in the quality of care (Alipour et al., 2012; Azizi \& Abdolkhani, 2012; Diamond, Johnson, Padman, Zheng, \& Payne, 2000; Jamal, McKenzie, \& Clark, 2009; Karami, 2015). These improvements are evident in areas such as cardiac care, intensive care, prescription drugs, and nursing (Karami, 2015; Bertsche et al., 2010; Lyerla, LeRouge, Cooke, Turpin, \& Wilson, 2010; Rollman et al., 2002; Walsh et al., 2010).

The acceleration of diagnosis and treatment and increase in productivity and medical research has been found to show the greatest effect from IT. This is consistent with results of other studies (Shokrizadeharani \& Karami, 2012; Shahabipour \& Mostafavi, 2011; Alipour, Erfannia, Karimi, \& Aliabadi, 2013). The present study revealed that physicians had a more positive viewpoint about the effect of IT on improving the healthcare system and on medical studies than other personnel. Alipour demonstrated that physicians primarily use computers for research and their findings are consistent with the findings of the present study (Alipour et al., 2013). Karami stated that the use of the intelligent systems to access the latest medical findings is required when making the best decisions about treatment of patients and accessing patient information to minimize errors and repetition of lab work while accelerating treatment and diagnosis (Karami, 2015).

Several studies have confirmed an increase in productivity, a decrease in administrative costs, a decrease in repetitive works and lab tests from the use of IT (Karami, 2015; Moradi, Sarbaz, Kimiafar, Shafiei, \& Setayesh, 2009; Field et al., 2008; McMullin et al., 2004; Niès et al., 2010; Karami \& Safdari, 2016). These are the major applications of IT in health care (Dehghan \& GHhorbani, 2004) and accelerate service delivery, reduce costs (Hoshang, \& Rahimov, 2011), and increase productivity.

The most effective strategies for improving the healthcare system mentioned in the present study were the use of standardized messaging and integrated systems for patient records, which was similar to the results of Shokrizadeharani (Shokrizadeharani \& Karami, 2012). Other studies have demonstrated that an important benefit of IT in the healthcare system is integrated access to patient records (Jamal et al., 2009; Walsh et al., 2010). Several studies have suggested that integrated health information increases productivity and decreases errors associated with human shortcomings (Shahabipour \& Mostafavi, 2011).

It should be noted that health care information is traditionally stored in different formats in various systems, when using the messaging standards. The different formats of messaging standards make possible the information transfer and sharing between multiple systems (Ahmadi, Rezaeihachesoo, \& Shahmoradi, 2008), which highlights their substantial importance in the integration of health data. Therefore it is necessary to use exchanging and messaging standards for integration of systems to provide complete access patient information from different periods of time and medical centers (Karami, 2015). 
The research population believed that development of similar mechanisms for protection of data confidentiality and security is essential to increasing the effect of IT in health care. The development of security solutions to protect the privacy of patients and therapists requires the creation of a safe environment for sharing information and providing electronic health services (Ahmadi, Dehghani Mahmoodabadi, Foozonkhah, 2012). Adoption of security mechanisms to protect the information against hackers is basic to the design of systems (Karami \& Safdari, 2016). When uncertainty exists about the confidentiality of information, confidentiality can reduce the degree of honesty in which patients provide medical information. This will decrease the benefit of the system, such as increased access, improved quality, and decreased costs for health care (Karami, Safdari, \& Rahimi, 2012).

Proper functioning of the health information infrastructure depends on the principles of confidentiality and security of health information. Lack of clear and specific guidelines for confidentiality of patient information in Iran and the tendency of institutions to operate according to their own tastes can lead to violation of patient rights (Aminpour, 2008). It is necessary to develop similar mechanisms for confidentiality and security of data and the research population correctly recognized this requirement.

Another finding of this study was the promotion of acceptance of computer data by legal authorities; this was identified as a challenge for telemedicine. It is necessary for the Ministry of Health to adopt specific rules and mechanisms to solve this problem (Ahmadi et al., 2012).

The relationship of the attitudes of the research population towards the effect of IT on improving the healthcare system demonstrated that physicians had a significantly more positive outlook about the effects of IT on self-care, medical research, reducing repetitive lab work, and accelerating treatment and diagnosis compared to the other clinicians.

In fact, the reason of more positive view of physicians than the other study groups is that they are involved in patient care directly and therefore they could be have better perceive for the positive impacts of information technologies in the fast development of medical sciences. As well as, other phenomena, that have positive effects in providing more quality services to patients, Can mention to evidence-based medicine, decision support systems, robotics surgeries, tele-consulting and tele-care.

Physicians also accepted computerized physician orders as an effective solution to improving healthcare; this is consistent with reports from other studies (Shokrizadeharani \& Karami, 2012; Alipour et al., 2012; Karami, 2014; Alipour et al., 2013; Safdari et al., 2013; Farzandipour, Sadoughi, Ahmadi, \& Karimi, 2008). Because physicians are the main health care providers and play a major role in the documentation and issues related to treatment of the disease, their acceptance and a positive viewpoint toward IT can have a significant effect on the successful implementation of these technologies.

Table 5 shows a significant and positive relationship between the effect of IT on improving the healthcare system and suggested solutions for its promotion. The results revealed that increasing positive perspective of people towards the effect of IT in treatment, education, research, and management can affect the implementation and adoption of these technologies positively. Positive perspective of users leads to better selection of systems and decreases challenges to their application. A meaningful relationship was found between the proposed solutions for improving the healthcare system and increasing the effect of IT on this system. It can be concluded that users with positive perspective can develop written plans and determine strategies and policies needed for successful implementation of health IT.

\section{Conclusion}

The positive viewpoints of the research population showed that there is readiness among clinicians for implementation of IT in the hospitals and to take steps for implementing electronic health records. It is necessary to identify the problems of and barriers to use of this technology. An appropriate organizational culture and provision of training to therapists who act as system users is essential to increasing the effect of IT on the healthcare system.

The present study revealed that physicians play important roles in successful implementation of IT because they are directly involved in the treatment of the patients. Their opinions should be considered when creating the type of system. The importance of budgeting should be considered because application of these systems is capital intensive. It should also be recognized that comprehensive application of these systems requires acceptance of the information by legal circles.

\section{Acknowledgments}

The authors would like to thank all those who assisted and participated in this study. 


\section{Funding}

The study has been carried out without external funding.

\section{Competing Interests Statement}

The authors declare that there is no conflict of interests regarding the publication of this paper.

\section{References}

Ahmadi, M., Dehghani Mahmoodabadi, A., \&Foozonkhah, Sh. (2012). Messaging standards for electronic health records in selected organizations. Health Information Management, 9, 161-71.

Ahmadi, M., Sadoughi, F., Gohari, M., \& Jeddirangraz, F. (2011). Personal Health Record, Information Technology in Future Health Care System: Physicians and Nurses View Point. Health Information Management, 8(1), 1-13.

Ahmadi, M., Rezaeihachesoo, P., \& Shahmoradi, L. (2008). Electronic health record: structure content, and evaluation. Tehran: Jafari Press.

Ajami, S., Ketabi, S., Saghaeiannejad, S., \& Heidari, A. (2012). Requirements and areas associated with readiness assessment of Electronic Health Records implementation. Journal of Health Administration, 14, 71-79.

Alipour, J., Erfannia, L., Karimi, A., \& Aliabadi, A. (2013). Electronic Health Record Acceptance: A Descriptive Study in Zahedan: Southeast Iran. $J$ Health Med Inform, 4(120), 2. http://dx.doi.org/10.4172/2157-7420.1000120

Alipour, J., Hayavihaghighi, M. H., Khorami, F., Hoseniteshnizi, S., Bonyani, L., Karimi, F., \& Baniasadi, N. (2012). The impact of Medical Information Systems on health care quality and factors affecting the use of these systems from physician's viewpoints in Hormozgan University of Medical Sciences. Journal of Health Administration, 14(46), 47-57.

Aminpour, F. (2008). Medical ethics challenges in the information societies. Iranian Journal of Medical Ethics and History of Medicine, 1(1), 53-60.

Azizi, A., \& Abdolkhani, R. (2012). The case study of effect of Hospital Information System in improvement of Razi hospital performance. Jentashapir Journal of Health Research, 2, 185-90.

Baghbaniyan, A., \& Ghanehpour, M. (2000, May). Use of computer and hospital information system (HIS). Paper presented at the national congress "role of management in healthcare delivery" (RMHCD), Kerman, Iran. Retrieved from http://www.ensani.ir/storage/Files/20101210200644-63246.pdf

Barzekar, H., \& Karami, M. (2014). Organizational Factors that Affect the Implementation of Information Technology: Perspectives of Middle Managers in Iran. Acta Inform Med., 22, 325-28. http://dx.doi.org/10.5455/aim.2014.22.325-328

Bates, D. W., Cohen, M., Leape, L. L., Overhage, J. M., Shabot, M. M., \& Sheridan T. (2001). Reducing the frequency of errors in medicine using information technology. $J$ Am Med Inform Assoc., 8, 299-308. http://dx.doi.org/10.1136/jamia.2001.0080299

Bertsche, T., Pfaff, J., Schiller, P., Kaltschmidt, J., Pruszydlo, M. G., Stremmel, W., ... Encke, J. (2010). Prevention of adverse drug reactions in intensive care patients by personal intervention based on an electronic clinical decision support system. ICM, 36(4), 665-72.

Buntin, M. B., Burke, M. F., Hoaglin, M. C., \& Blumenthal, D. (2011). The benefits of health information technology: A review of the recent literature shows predominantly positive results. Health Affairs, 30, 464-71. http://dx.doi.org/10.1377/hlthaff.2011.0178

Dargahi, H., Mahmoodi, M., \& Torabi, M. (2006). Assessing the viewpoint of faculty members of medical record departments in Iran about the impact of Information Technology on health system 2004. ISMJ, 9(1), 93-101.

Dehghan, R., \& Ghorbani, V. (2004). The development of e-health: A strategic necessity for the health care system. Health Information Management, 1(2), 57-70.

Diamond. H., Johnson, M. P., Padman, R., Zheng, K., \& Payne, V. L. (2000). Clinical Reminder System: A Relational Database Application for Evidence-Based Medicine Practice. Paper presented at INFORMS Spring National Conference; Salt Lake City, Utah. Retrieved from http://www.heinz.cmu.edu/research/88full.pdf 
Farzandipour, M., Sadoughi, F., Ahmadi, M., \& Karimi, I. (2008). Designing a Confidentiality Principles Model of Electronic Health Record for Iran; 2007. Journal of Health Administration, 11(33), 33-47.

Ferrara, F. (1996). Architecture of health information systems. State of the art and new perspectives. Rays, 21(2), $152-72$.

Field, T. S., Rochon, P., Lee, M., Gavendo, L., Subramanian, S., Hoover, S., Baril, J., \& Gurwitz, J. (2008). Costs associated with developing and implementing a computerized clinical decision support system for medication dosing for patients with renal insufficiency in the long-term care setting. $J$ Am Med Inform Assoc., 15, 466-72. http://dx.doi.org/10.1197/jamia.M2589

Hoshang, S., \& Rahimov, H., (2011). The role of information technology in the development of medical centers; case studies of Emam Hossein hospital in Shahrood city. Paper presented at the first Congress of the information technology application in health; Sari, Iran. Retrieved from http://www.civilica.com/Paper-CITH01-CITH01_096.html

Hosseini, M., \& Asefzadeh, S. (2009). Comparing the importance and planning of information technology in education and general hospitals of Iran University of Medical Sciences 2006. JQUMS, 13(1), 87-93.

Jamal, A., McKenzie, K., \& Clark, M. J. (2009). The impact of health information technology on the quality of medical and health care: A systematic review. HIMJ, 38(3), 26. http://dx.doi.org/10.1177/183335830903800305

Karami, M. (2015). Clinical decision support systems and medical imaging. Radiology management. March/Apr, 25-32.

Karami, M., \& Safdari, R. (2016). From Information Management to Information Visualization: Development of $\begin{array}{llll}\text { Radiology Dashboards. } & \text { Applied } & \text { Clinical } & \text { Informatics, }\end{array}$ http://dx.doi.org/10.4338/ACI-2015-08-RA-0104

Karami, M., Safdari, R., \& Rahimi, A. (2012). Effective radiology dashboards: Key research findings. Radiology management, 35(2), 42-5.

Karami, M. (2014). A design protocol to develop radiology dashboards. Acta Inform Med., 22(5), 341-6. http://dx.doi.org/10.5455/aim.2014.22.341-346

Kumar, P. (2012). Application of information and communication technology (ICT) by medical students: A study of Government Medical College, Chandigarh, India. Int. J. Lib. Inf. Sci., 4(3), 45-51. http://dx.doi.org/10.5897/IJLIS12.001

Lyerla, F., LeRouge, C., Cooke, D. A., Turpin, D., \& Wilson, L. (2010). A nursing clinical decision support system and potential predictors of head-of-bed position for patients receiving mechanical ventilation. AJCC, 19(1), 39-47. http://dx.doi.org/10.4037/ajcc2010836

McMullin, S. T., Lonergan, T. P., Rynearson, C. S., Doerr, T. D., Veregge, P. A., \& Scanlan, E. S. (2004). Impact of an evidence-based computerized decision support system on primary care prescription costs. Ann Fam Med., 2, 494-8. http://dx.doi.org/10.1370/afm.233

Moradi, G.h., Sarbaz, M., Kimiafar, Kh., Shafiei, N., \& Setayesh, Y. (2009). The role of hospital information system on Dr Sheikh Hospital performance promotion in Mashhad. Health Information Management, 5(2), $159-66$.

Nasiripour, A. A., Rahmani, H., Radfar, R., \& Najafbeigi, R. (2012). Effective elements on e-health deployment in Iran. AJBM, 6, 5543-50. http://dx.doi.org/10.5897/AJBM11.2791

Nies, J., Colombet, I., Zapletal, E., Gillaizeau, F., Chevalier, P., \& Durieux, P. (2010). Effects of automated alerts on unnecessarily repeated serology tests in a cardiovascular surgery department: A time series analysis. BMC Health Services Research, 10, 70. http://dx.doi.org/10.1186/1472-6963-10-70

Nematbakhsh, M. (2015). Research in the evolution plan of health system. Iranian Journal of Medical Education, 15(11), 64-6.

Phunchongharn, P., Hossain, E., Niyato, D., \& Camorlinga, S. (2010). A cognitive radio system for e-health applications in a hospital environment. Wireless Communications, IEEE, 17(1), 20-8. http://dx.doi.org/10.1109/MWC.2010.5416346

Rezaeihachesoo, P., Fozoonkhah, S., Safaei, N., \& Afshar, H. L. (2010). Organisational and Health Care Process Management with Use of Information Technology. Health Information Management, 7, 341-52. 
Rollman, B. L., Hanusa, B. H., Lowe, H. J., Gilbert, T., Kapoor, W. N., \& Schulberg, H. C. (2002). A randomized trial using computerized decision support to improve treatment of major depression in primary care. JGIM, 17(7), 493-503. http://dx.doi.org/10.1046/j.1525-1497.2002.10421.x

Rozenblum, R., Jang, Y., Zimlichman, E., Salzberg, C., Tamblyn, M., Buckeridge, D., ... Tamblyn, R. (2011). A qualitative study of Canada's experience with the implementation of electronic health information technology. CMAJ, 183, E281-E8. http://dx.doi.org/10.1503/cmaj.100856

Sadoughi, F., Ahmadi, M., Gohari, M., \& Rangrez Jeddi, F. (2010). Attitude of inpatients about information technologies literacy. Journal of Health Administration, 13(40), 31-40.

Shahabipour, A., \& Mostafavi, M. (2011). A model for the implementation of electronic health records; subsystem of electronic city. Bimonthly Artificial Intelligence and Precision Instruments, 2(26), 42-3.

Shokrizadeharani, L., \& Karami, M. (2012). The Effects of Information Technology on the Improvement of Health Systems in the Viewpoint of the Staff of Beheshti Hospital, Kashan. Health Information Management, 8, 835-41.

Trimm, J. (1990). Operations research and information technology for materiel management in the 1990s. Hosp Mater Manag Q., 11(3), 20-5.

Walsh, M. N., Yancy, C. W., Albert, N. M., Curtis, A. B., Stough, W. G., Gheorghiade, M., ... Fonarow, G. C. (2010). Electronic health records and quality of care for heart failure. Am Heart J., 159(4), 635-42. http://dx.doi.org/10.1016/j.ahj.2010.01.006

\section{Copyrights}

Copyright for this article is retained by the author(s), with first publication rights granted to the journal.

This is an open-access article distributed under the terms and conditions of the Creative Commons Attribution license (http://creativecommons.org/licenses/by/3.0/). 